\title{
Junior doctors and emergency tranquillisation of elderly, confused patients: a survey
}

\author{
Simon Thacker
}

This paper presents the results of a survey of funior doctors' opinions concerning the emergency trenquillisetion of cecutely disturbed, contused elderty patients. Although the mejortty of reapondents gave recommendations within current guidelines, there were lange variations in ctug does, and the choice of peychotropic agent may hove been determined more by avallability than rational prescribing proctice.

Medical and psychiatric trainees often deal with elderly confused patients who are acutely disturbed. If the patient lacks insight and is seriously resisttve, emergency tranquillisation has an important role in clinical management. Most modern authorities recommend that in these circumstances the neuroleptic haloperidol is the drug of choice, because of its relattve freedom from cardiac, autonomic, and respiratory side-effects. Due to the risk of disabling extrapyramidal sideeffects and the relattvely prolonged half-life in the elderly, titration up from a low starting dose is advised (Lipowsk, 1989; Fairweather, 1990; Burns \& Baldwin, 1994). The author's informal inquiries from Senior House Officers (SHOs) working in the Department of Health Care of the Elderly, University Hospital Nottingham, suggested that many junior doctors were unsure of what drug strategy to use in these circumstances and therefore an enquiry into current opinion among trainees seemed appropriate.

\section{The study}

All doctors in general professional training and working at the time of survey (September 1994) in a medical (internal or geriatric) or psychiatric post in Nottingham were identified and sent the following case vignette:

"A previously healthy 80-year-old man of average build was admitted today with a chest infection. severe dehydration and confusion. He requires fluids and antibiotics urgently, but offers of oral fluids and medication have been thwarted by threats and punches. All attempts to orlentate and reassure him have failed."
Respondents were asked to specify their choice of initial pharmacological management (if any). including dose and route. Assuming that after one hour there was little alteration in the patient's condition, they were asked to specify their next pharmacological intervention (if any). Finally, they were asked what further psychotropic drug they would prescribe (if any), if after another hour the patient was less disturbed, accepting oral medication, but still confused (the follow-up phase).

\section{Findings}

Seventy-eight doctors were contacted, comprising 44 medical senior house officers (SHOs) and $\mathbf{3 4}$ psychiatric $\mathrm{SHOB}_{3}$ and registrars. There were 46 (59\%) valid responses with a higher response rate from the psychilatrists (76\% v. 45\%).

Thirty $(65 \%)$ respondents, divided equally between medical and psychiatric trainees, advised intramuscular haloperidol in doses at or below $5 \mathrm{mg}$ as their first-line parenteral tranquilliser, while three $(7 \%)$ others recommended either haloperidol or droperidol at a dose of $10 \mathrm{mg}$ intramuscularly. Only four (9\%) doctors would have given intramuscular chlorpromazine as their initial sedation and then in doses no greater than $50 \mathrm{mg}$. Two others prescribed intramuscular thioridazine, a product not available in the United Kingdom (British Medical Associaton and Royal Pharmaceutical Society of Great Britain, 1994).

Four (9\%) replies, all from psychiatrists, indicated benzodiazepines for first-line parenteral tranquillisation (diazepam $5 \mathrm{mg}$ intravenously. diazepam $5 \mathrm{mg}$ intramuscularly, lorazepam up to $4 \mathrm{mg}$ intramuscularly in two cases). Three other psychiatrists indicated intramuscular lorazepam (dose 2-4 mg) if intramuscular neuroleptics had failed. Another psychiatric respondent recommended zuclopenthixol acetate (Clopixol Acuphase) as the first-line treatment.

One respondent would not prescribe parenteral psychotropic medication at any stage, indicating 
that $10 \mathrm{mg}$ of thioridazine may be given orally if the patient agreed. Another respondent would not have prescribed any psychotropics in the acute situation, when aggression and resistiveness were the key problems, but would have considered giving a single dose of $1.5 \mathrm{mg}$ oral haloperidol in the follow-up phase. Five further respondents indicated that oral sedation should be offered first (two prescribing chlormethiazole, one promazine, one thioridazine and one haloperidol) before opting for intramuscular therapy if unsuccessful; two others would have withheld psychotropics initially before giving a parenteral formulation if there was no improvement after one hour.

In the follow-up phase, $15(33 \%)$ respondents five medical, ten psychiatric - would not have prescribed any further psychotropic medication; 19 (41\%) - 11 medical, 8 psychiatric - prescribed a phenothiazine (thioridazine, except one instance of promazine and one of chlorpromazine); 11 (24\%) - four medical, seven psychiatric-favoured a butyrophenone (haloperidol, except one case of droperidol) and one psychiatrist prescribed diazepam $10 \mathrm{mg}$ orally up to four times daily p.r.n. (as required). Of those who recommended a phenothazine, six prescribed on a p.r.n. basis. The maximum possible daily dose under p.r.n. prescribing was $400 \mathrm{mg}$ of thioridazine compared with the maximum under regular prescribing of $200 \mathrm{mg}$ of promazine, a less potent tranquilliser. Fifteen of the 19 responses indicated maximum permissible doses of thioridazine or chlorpromazine below $150 \mathrm{mg}$ daily, with the lowest dose of phenothiazine prescribed at this time being $5 \mathrm{mg}$ thioridazine three times daily. The prescription of follow-up butyrophenones was similarly varied but with no prescribing on a p.r.n. basis, although two respondents gave a range of doses. The maximum permissible daily doses were for droperidol, up to $30 \mathrm{mg}$ fourhourly and haloperidol $10 \mathrm{mg}$ three hours daily, which contrasted with a minimum of haloperidol $0.5 \mathrm{mg}$ twice daily. All other prescriptions indicated a maximum daily dose of haloperidol below $10 \mathrm{mg}$. However, if $10 \mathrm{mg}$ of haloperidol is equipotent to $500 \mathrm{mg}$ of chlorpromazine or thioridazine (Bazire, 1994) then butyrophenones were suggested in much higher equivalent doses than phenothiazines.

\section{Comment}

This survey is the first to examine the prescribing opinions of junior doctors likely to be required to rapidly tranquillise acutely disturbed elderly patients. In spite of the shortness of the questionnaire, the relatively low response rate may be explained by the fatigue induced by the large number of questionnaires sent to members of the medical profession. A further deficiency in the study was the lack of systematically recorded data on the respondents' past medical experience, in particular whether they had worked in geriatrics or psychogeriatrics.

Most replies indicated initial drug management broadly in keeping with published guidelines, i.e. a small dose of intramuscular haloperidol. Only a few respondents suggested excessive doses of a butyrophenone (above $5 \mathrm{mg}$ of intramuscular haloperidol or droperidol) and only one recommended the medium-term injectable neuroleptic. zuclopenthixol acetate, which would be inadvisable in view of its prolonged duration of action (Thompson, 1994). The unpopularity of intramuscular chlorpromazine may reflect awareness of the potentially dangerous hypotenstve, arrythmogenic and anticholinergic effects of the more sedative phenothiazines, even though this did not translate into a reluctance to prescribe oral thioridazine in the follow-up phase, when this drug was the commonest prescription. The ready avallability of oral thioridazine on both medical and psychogeriatric wards may explain its popularity. In comparison, oral haloperidol comes in a wider range of tablet sizes $(0.50-20 \mathrm{mg})$, making it difficult for doctors to remember doses and for pharmacists to determine the appropriate ward stock. Greater liaison between doctors and pharmacists on the issue of emergency tranquillisation would be valuable.

The combined use of neuroleptics and benzodiazepines is recognised as an effective means of tranquillisation in general psychiatric settings (Pllowsky et al, 1992), but is not readily applicable to elderly people, in whom benzodiazepines risk worsening delirious states by both a direct effect on the cortex and by depressing the respiratory centre in those with compromised lung function (Dia et al, 1994). Several respondents indicated benzodiazepines as first or second line tranquillisation. It would be wrong to suggest that benzodiazepines are contraindicated in all disturbed, acutely confused elderly patients, and clinicians must judge the riskbenefit ratio in each case: clearly, if alcohol withdrawal is strongly suspected benzodiazepines might be appropriate. In this study, they were recommended solely by psychiatric trainees.

The follow-up phase produced a variety of responses, with a broad range of doses of either a phenothiazine or butyrophenone. Some of the p.r.n. prescribing would have allowed the administration of very high doses of neuroleptics compared with the prescriptions for regular dosing and this suggests the need for doctors to record the maximum total daily dose. The risks of excessive doses being prescribed were particularly high with haloperidol and droperidol and have been prevlously recorded in the general psychiatric literature (Baldessarini et al, 1984; Cunnane, 1994), highlighting the need for junior 
doctors to receive continuing education on the use of psychotropic drugs. Indeed, an addendum to several of the responses asked for feedback and guidance.

\section{Acknowledgement}

I would like to thank Professor T. Arie for his advice in preparing this manuscript.

\section{References}

BALDESSARINI, R. J., KATZ, B. \& COTTON, P. (1984) Dissimilar dosing with high-potency and low-potency neuroleptics. American Joumal of Psychiatry. 141, 748-752.

Bazze, S. (1994) Psychotropic Drug Dtrectory 1994. Lancaster: Quay Publishing Ltd.

BRTISH MEDICAL ASSOCLATION AND ROYAL PHARMACEUTICAL SOCIETY OF GREAT BRTAN (1994) British National Formulary, No. 28. London: Britlsh Medical Assoctation and The Pharmaceutical Press.

BURNS, A. \& BALDWIN, R. (1994) Prescribing psychlatric drugs for the elderly. Advances in Psychiatric Treatment. 1. 23-31.
Cunnane, J. G. (1994) Drug management of disturbed behaviour by poychiatrists. Psychiatric Bulletin, 18. 138-139.

Di. A. R. RANGa. K. \& Krishnan. R. (1994) Psychopharmacological treatment of anxiety disorders. In Principles and Practice of Gerlatric Psychiatry leds J. R. M. Copeland, M. T. Abou-Saleh \& D. G. Blazer), pp. 741-749. Chichester: John Wiley.

FAIRWEATHER, S. (1990) Delirium. In Psychiatry in the Elderly (eds R. Jacoby \& C. Oppenheimer), pp. 647-675. Oxford: Oxford Untversity Press.

LPOWSK, Z. J. (1989) Delirium in the elderly patient. New England Journal of Medictie, 320, 578-582.

Pilowsky, L. S., Ring, H., Shrine, P. J., et al (1992) Rapid tranquillisation, a survey of emergency prescribing in a general psychiatric hospital. British Journal of Psychiatry, 160, 831-835.

THOMPSON, C. (1994) The use of high-dose antipsychotic medication. British Joumal of Psychiatry, 164, 448-456.

Simon Thacker, Senior Registrar in Old Age Psychiatry, Department of Health Care of the Elderly, Medical School, University Hospital, Nottingham NG7 2UH

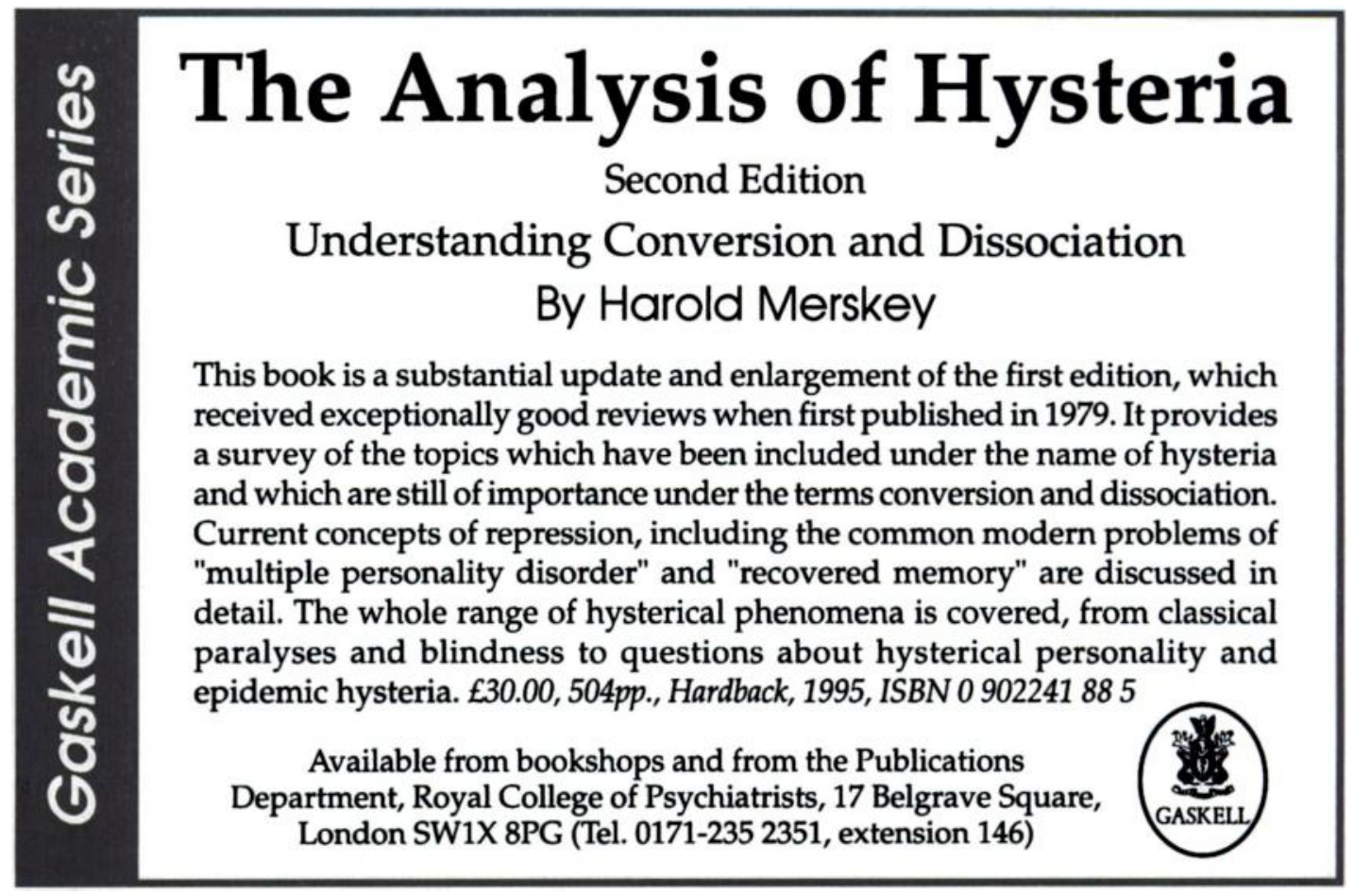

